Historic, archived document

Do not assume content reflects current scientific knowledge, policies, or practices. 



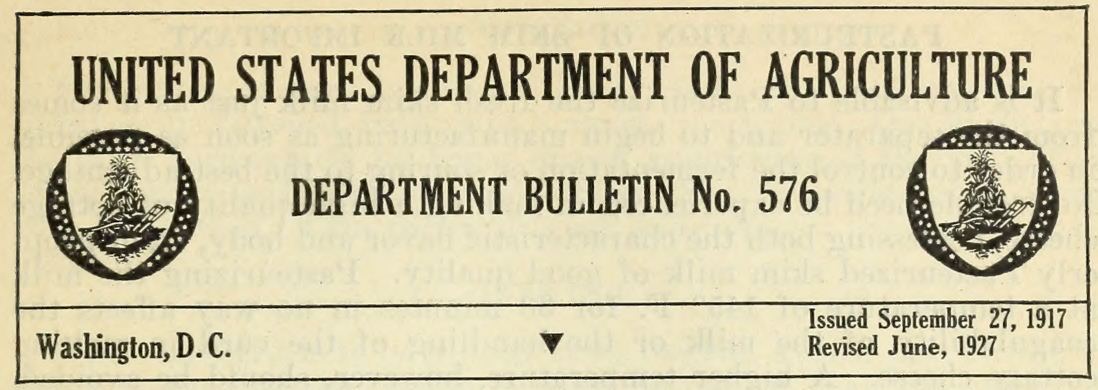

\section{THE MANUFACTURE OF COTTAGE CHEESE IN CREAMERIES AND MILK PLANTS}

By ARnold O. DAhlberg, ${ }^{1}$ Dairy Manufacturing Specialist; revised by K. J. Matheson, Dairy Manufacturing Specialist, Bureau of Dairy Industry

\begin{tabular}{|c|c|c|}
\hline Page & & Page \\
\hline 1 & $\begin{array}{l}\text { Method of manufacture-Continued. } \\
\text { Draining and washing the curd }\end{array}$ & - \\
\hline 2 & Salting and creaming & 6 \\
\hline 2 & Packing and marketing & \\
\hline$\overline{2}$ & Yield of cheese & 7 \\
\hline$\frac{2}{3}$ & Quality of cheese & \\
\hline$\stackrel{3}{3}$ & Buttermilk as material for cheese & 10 \\
\hline 3 & Making buttermilk cheese & 11 \\
\hline 3 & Markets and prices & 11 \\
\hline & Summary_.......... & \\
\hline
\end{tabular}

Cottage cheese, properly made, offers a most palatable and nutritious article of food at a price relatively low compared with the cost and nutritive value of many other foods, and the demand for it is increasing with the greater knowledge of its true value as a food. This variety of cheese is made from skim milk. The simplicity of the method of manufacture recommends its adoption by creameries and milk plants having skim milk which it is desired to dispose of to good advantage. Very little additional equipment is required, and the cost of manufacture is low, which enables the creamery to pay the patrons a good price for the skim milk.

\section{GOOD RAW MATERIAL ESSENTIAL}

As the quality of cottage cheese is entirely dependent upon flavor and texture, it is very important to have milk of a good clean flavor, free from any foreign odors. 'The maker can control the texture of cheese by the process of making; but if the flavor is to be controlled, good raw material is necessary.

${ }^{1}$ Mr. Dahlberg resigned Jan. 15, 1920. $48013^{\circ}-27$ 


\section{PASTEURIZATION OF SKIM MILK IMPORTANT}

It is advisable to Pasteurize the fresh skim milk just as it comes from the separator and to begin manufacturing as soon as possible, in order to control the fermentation or souring to the best advantage. No trouble need be experienced in making a high quality of cottage cheese, possessing both the characteristic flavor and body, from properly Pasteurized skim milk of good quality. Pasteurizing the milk at a temperature of $145^{\circ} \mathrm{F}$. for 30 minutes in no way affects the coagulability of the milk or the handling of the curd in making cottage cheese. A higher temperature, however, should be avoided, as it gives a fine curd which is much harder to handle during the process of manufacture. Perhaps the greater portion of the cottage cheese used is made from raw skim milk, but the benefits to be derived from proper Pasteurization are so great as to make it highly advisable. Pasteurization adds but little to the cost of making and has the following important points in its favor:

1. It insures a food product free from all danger of disease-producing bacteria.

2. It makes possible a more perfect control of souring through the use of pure-culture starters, thus insuring the formation of an acid curd giving the characteristically mild, sour-milk flavor so much desired.

Pasteurization requires little additional work, if suitable equipment is available. The use of a Pasteurizing vat, so elevated as to allow the Pasteurized milk to run into the making vat by gravity, gives most satisfactory results.

\section{EQUIPMENT REQUIRED}

The equipment needed for making cottage cheese, in addition to that already in the creamery or milk plant, depends upon the apparatus on hand and whether the skim milk is to be Pasteurized. When a Pasteurizer and a channel-bottomed vat are available, very little expense is necessary. The following-named apparatus will be needed: Pasteurizer, channel-bottomed cheese vat, curd knives, curd pail, vat whey strainer, floating dairy thermometer, and an outfit for determining acidity.

\section{PASTEURIZER}

The holding system of Pasteurization is to be preferred. It requires a Pasteurizing vat which may also be used for cooling the skim milk to the ripening temperature, after which the milk is run into the making vat. The skim milk for more than one batch of cheese may be handled in one Pasteurizing vat, provided all of it does not have to be taken care of at once.

In case the flash method of Pasteurization is used, it is advisable to guard against having the temperature too high. From $165^{\circ}$ to $170^{\circ} \mathrm{F}$. is about right.

\section{CHEESE VAT}

A Cheddar-cheese vat of the ordinary channel-bottomed type with steam and water connections is often used for the purpose of heating the curdled skim milk. 


\section{CURD KNIVES}

Two kinds of curd knives are used. Both are made of wire or metal strips fastened, half an inch apart, to a frame. One knife cuts the curd horizontally by being drawn lengthwise of the vat. The other cuts it vertically by being drawn, first, crosswise of the vat, then lengthwise. Thus the curd is cut into cubes.

CURD PAIL

When the curd is to be dipped from the vat, a curd pail having a flat side opposite the handle is more convenient than the ordinary round pail, because the curd at the bottom can be scooped up more easily.

\section{VAT WHEY STRAINER}

The strainer commonly used is of metal, cylindrical in shape, about 5 inches in diameter, with a spout at the bottom which just fits the spigot opening. The strainer is placed in the vat outlet, which allows the whey to drain off, leaving the curd.

\section{METHOD OF MANUFACTURE}

\section{RIPENING THE MILK}

The object of ripening is to obtain the characteristically mild, sourmilk flavor and to develop the acidity necessary to coagulate the milk and bring about a separation of the whey from the curd when the coagulated milk (or coagulum) is heated. The temperature of ripening depends upon the time at which the cheese is to be made and the quantity of starter added.

Fresh skim milk should be set at a temperature which will produce a firm, smooth, uniform curd at the time of cutting. The ripening can be regulated by the temperature at which the milk is set and the quantity and kind of starter used. Pure cultures for starters with directions for use may be obtained at intervals from a commercial laboratory at moderate cost. Experience soon will show the right combination of starter and temperature to be used for best results under existing conditions. A good, active, clean-flavored starter should be added at the rate of 2 to 10 per cent of the skim milk. Two or 3 per cent of starter is usually sufficient. When a very rapid coagulation is desired, as much as 10 per cent may be needed. The setting temperature is about $70^{\circ}$ to $75^{\circ} \mathrm{F}$. in the summer and $80^{\circ}$ to $85^{\circ} \mathrm{F}$ in the winter. Depending on the temperature and the quantity of starter employed, a smooth, uniform curd is usually obtained in 10 to 15 hours.

Raw skim milk of good flavor, allowed to sour naturally, usually develops a well-flavored curd, but the probability of regularly obtaining a fine-flavored product is greatly increased by Pasteurization and the use of a good starter. A starter of poor quality should never be used, because by introducing undesirable fermentations it does more harm than good; in fact, it would be better to depend upon the natural souring of the skim milk than to use a poor starter. 


\section{CUTTING AND HEATING THE CURD}

The best time to cut the curd is shortly after it shows a firm and uniform coagulation, with an acidity of from 0.65 to 0.80 per cent, for at that stage a mild-flavored cheese is obtained and at the same time sufficient acid is present to give a clear separation of the whey from the curd. The object of cutting and heating is to get rid of the desired quantity of whey and to remove much of the acidity with the least possible loss of curd. The best method of cutting the curd is to use regular cheese-curd knives, described above, which cut the curd into fairly uniform cubes from which the whey can be expelled with but small loss of finely broken particles of curd passing through the drain cloth. To break the curd or coagulum with a

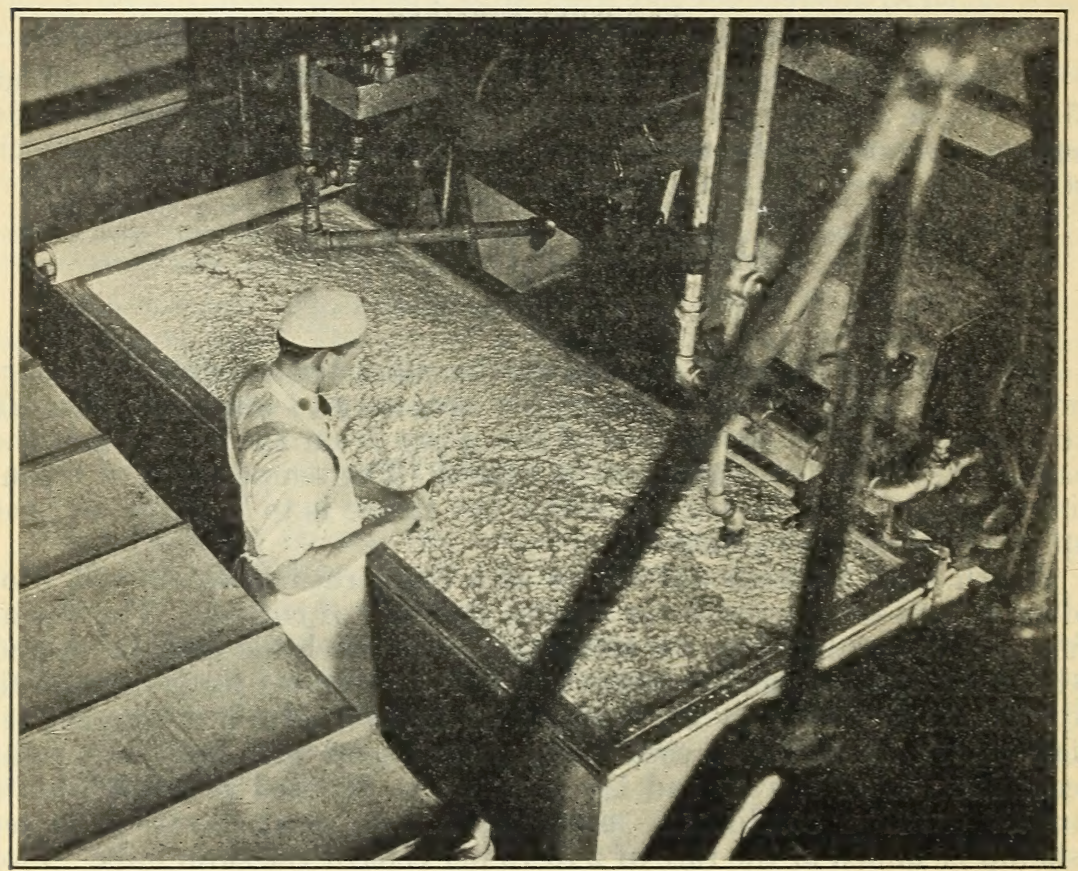

FIG. 1.-Stirring the curd during heating

stirrer produces too many fine particles of curd, which are easily lost in draining.

After the curd is cut, heat is turned under the vat, and the temperature is raised gradually to $115^{\circ}$ to $125^{\circ} \mathrm{F}$. At the Grove City, Pa., creamery, operated by the Bureau of Dairy Industry, a temperature of $120^{\circ}$ to $125^{\circ}$ has given best results. Formerly a temperature of $95^{\circ}$ to $105^{\circ}$ was used for heating the curd; but when the cheese is made in large quantities it seems better to use a higher heating temperature and then cool immediately with cold water. Variation in the heat requirement depends upon the quantity of milk, the degree of acidity, the length of the period of heating, and the texture of cheese desired. The curd should be stirred gently at intervals (fig. 1) to prevent its cooking on the sides and bottom of 
the vat. Too rapid heating or stirring tends to break the particles so that the resulting cheese does not have the proper flakes in the finished product. A wooden rake may be used for this purpose.

The texture of cottage cheese is controlled by the temperature at which the curd is heated, the length of time heated, and the extent of draining. Considerable variation as to temperature and time of heating and draining is found necessary, depending upon the condition of the curd.

Heating the curd to a temperature of $115^{\circ}$ to $125^{\circ} \mathrm{F}$. favors the rapid expulsion of whey, but care must be taken that the product does not become too tough and dry. Ordinarily one-half hour to one and one-half hours is required to heat a 5,000-pound vat of skim milk to this point, at which time the whey is generally removed. The usual test for judging the proper time to remove the whey is to squeeze a handful of the curd; if the curd particles cohere in a gelatinous mass, the curd is too soft; when the mass becomes open and porous, and readily breaks up on being rubbed between the hands, it is time to withdraw the whey. Experience will serve as a guide to the right length of time and the best temperature for heating.

\section{DRAINING AND WASHING THE CURD}

When the heating has continued for the proper length of time, the free whey is drawn off from the bottom of the vat through a strainer, which prevents the loss of curd particles. The curd must then be more thoroughly drained to bring it to a sufficiently dry condition for salting. Draining is sometimes done by transferring the curd to a drain rack lined with a cloth which serves as a filter. (Fig. 5.)

When the drain rack is used, the curd is transferred to it, and the greater portion of the remaining whey passes through the drain cloth quickly. An occasional manipulation of the drain cloth, rolling the curd back and forth in the rack, hastens drainage. The extent of drainage necessary depends upon the texture of cheese desired, the length of time the curd was previously heated, and the temperature of heating. If the whey is too completely separated from the curd the cheese may be too dry. To prevent this it is usual to wash the curd with cold water, which checks further separation yet at the same time removes the whey already separated. Free whey in the finished cheese tends to create a strong sour flavor. When the drain rack is used two people are required to handle the cheese effectively.

The trench system of drainage is now more extensively used than the drain-rack system. In this case the various operations of washing, salting, and creaming the cheese are all carried out in the original setting vat. The curd is washed first with warm water, then with lukewarm water, and finally with cold water. When the curd - has been partially cooled with cold water before the removal of the whey, it may be washed immediately with cold water. All the whey is removed before washing with cold water, unless the curd shows signs of becoming too dry, which does not happen frequently. If this should happen, however, the cold water is run in immediately, before much of the whey has been withdrawn. After the curd has been sufficiently washed the water is drained as completely as possible, and the curd is piled along each side of the vat, forming a 
trench in the middle. (Fig. 2.) This facilitates the escape of whey in a manner similar to that used in the manufacture of Cheddar cheese. The purpose of washing the curd is to prevent it from becoming too tough and rubbery, to eliminate the whey, and to increase its keeping quality. There should be little or no free whey in the cheese at the time of salting.

The advantages of the trench system over the drain-rack system are: (1) Less space is required; (2) drain cloths and special racks are eliminated, thereby reducing the cost of equipment and labor; (3) fewer curd particles are broken, thereby reducing the loss in the whey; (4) the curd requires less constant attention; (5) the curd may be salted and creamed while still in the vat and packed directly from the vat into the tubs.

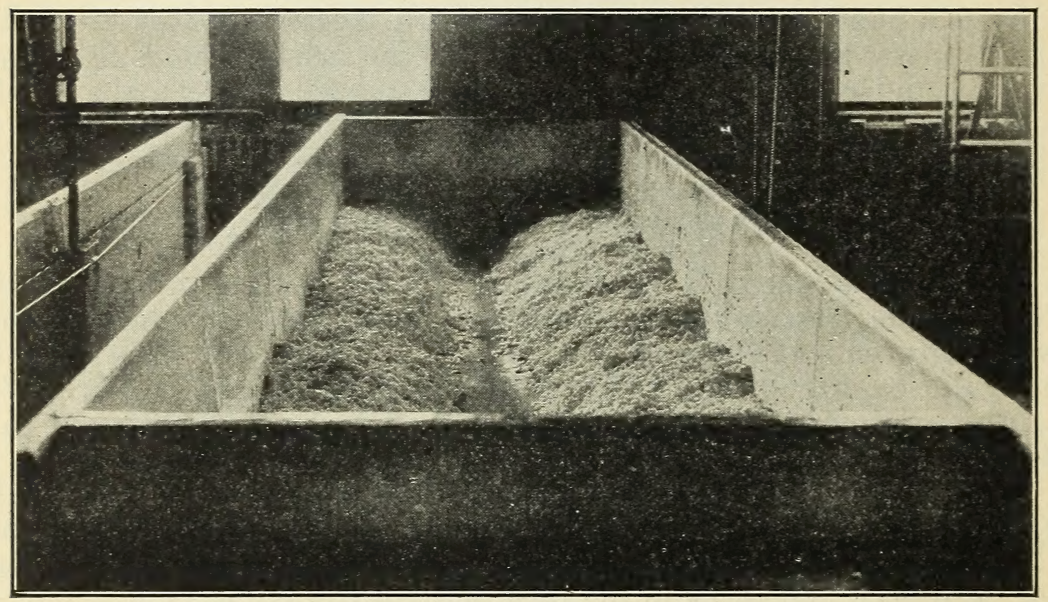

FIG. 2.-Cheese drawn to sides of vat, forming drainage trench in middle

\section{SALTING AND CREAMING}

When the curd has been drained sufficiently, salt is added and thoroughly worked into the cheese. The rate of salting is determined by the demand, some markets desiring a light-salted and others preferring a heavy-salted cheese. One and one-quarter pounds of salt to 100 pounds of cheese gives a medium-light-salted cheese satisfactory to the ordinary taste. From 3 to 4 ounces of salt to 100 pounds of milk is about the right degree of salting, and perhaps may be a better basis on which to begin. It usually is advisable to salt rather lightly, allowing the consumers greater opportunity to prepare the cheese to suit their individual tastes.

The addition of 1 pound of sweet cream to 10 pounds of cheese greatly increases palatability and is to be recommended, especially when it is desired to build up a trade appreciating high-quality products. The cream is worked into the cheese with the salt. The additional cost of cream is small when it is considered that each pound of cream adds a pound to the weight of the cheese. 


\section{PACKING AND MARKETING}

The ideal method of marketing is to pack the cheese in the small, single-service, sanitary, paraffined-paper containers, of which there are many kinds on the market. (Figs. 3 and 4.) The containers are convenient for the dealer to handle and are attractive to the buyer. While cartons add considerably to the cost of marketing, the extra price obtained for the product in that form usually compensates for the additional expense.

Recently a 12-ounce glass jar, provided with a proper cap and fitted into a regular pint milk-bottle crate, has been used successfully by certain distributors in marketing cottage cheese. A container of this type may be readily washed, sterilized, and used again.

Cheese to be shipped in bulk is best packed in butter tubs. (Fig. 5.)

Cottage cheese always should be packed immediately after it is salted and should be marketed within a few days, as it is perishable and deteriorates very quickly at ordinary room temperatures. To insure marketing in best condition and to prevent unnecessary loss,

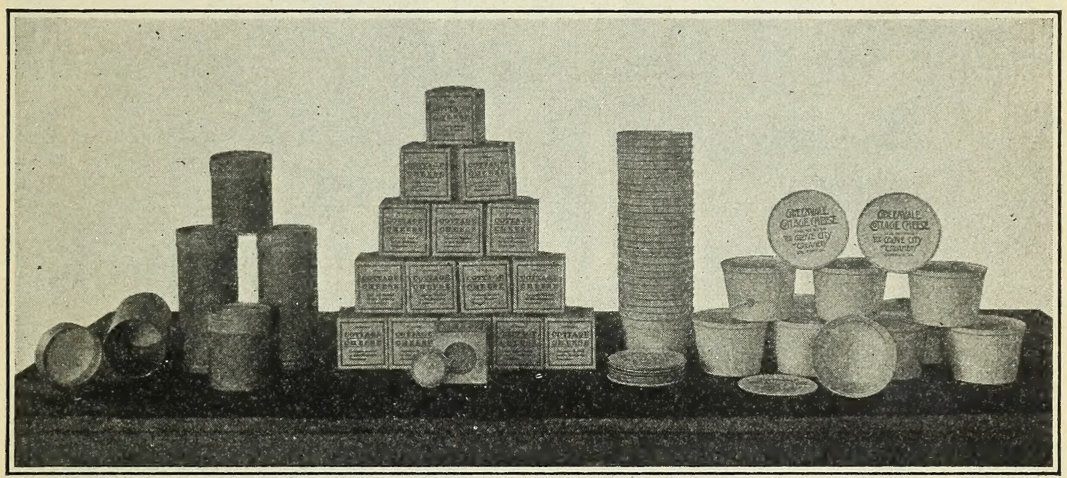

Fig. 3.-Cartons for marketing cottage cheese

it is important to have the cheese placed in the cooler or refrigerator immediately after it is made and to hold it at a low temperature until disposed of. Freshly made cheese should not be shipped until after it has been well cooled, because the warm curd is in a condition favoring fermentation and deterioration. It is advisable, therefore, to hold the freshly made cheese in the refrigerator overnight before making shipment.

\section{YIELD OF CHEESE}

The yield of cheese, which varies from 15 to 18 pounds from 100 pounds of skim milk, depends almost entirely upon the amount of moisture left in the curd and is controlled by the method of manufacture. The factors that influence, the percentage of moisture in the curd and determine the yield are:(1) Temperature of heating curdled milk (or coagulum); (2) length of time curd is heated; (3) extent of draining; (4) physical condition of the skim milk after curdling. 
The physical condition of the skim milk after curdling often has a marked influence upon the resulting yield. A weak, unevenly coagulated curd, when cut, produces a large quantity of fine particles, much of which is apt to be lost during drainage.

\section{QUALITY OF CHEESE}

Cottage cheese is judged by its flavor and texture. Flavor can be controlled by the use of clean, sweet, Pasteurized milk and the use of a good starter; but texture depends largely upon careful manipulation during the making and washing processes.

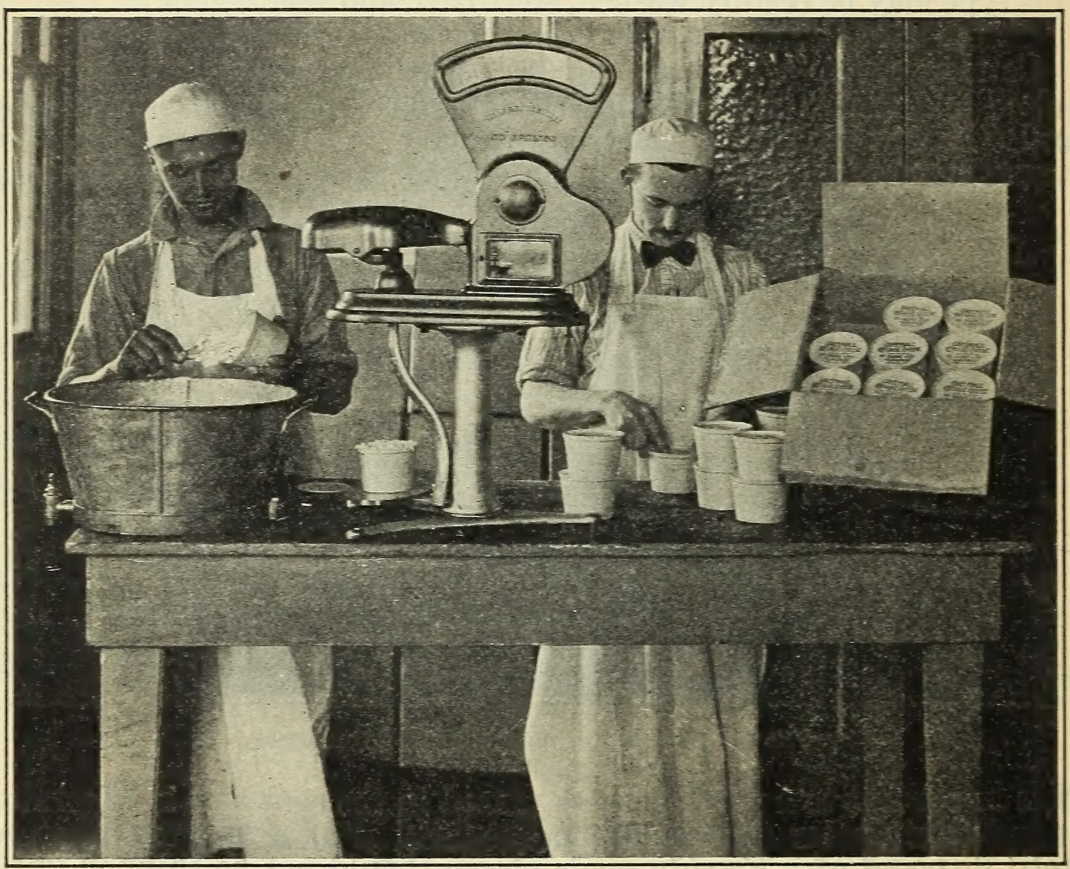

Fig. 4.-Packing the cheese in cartons

Cottage cheese should have a clean, mild acid flavor. Strong acid flavors are to be avoided. The body and texture of cottage cheese should be soft, smooth, and uniform throughout. The individual particles or flakes should be distinct, neither hard nor mushy, and of a size between that of a kernel of popcorn and one of field corn.

\section{COST OF MANUFACTURE}

Although the cost of manufacture depends somewhat upon the cost of fuel and labor, it is influenced more by the volume of business. The table on page 10, obtained from records made in 1922 and showing averages for a two-months' period when the volume of business was about 125,000 pounds of skim milk each month, gives a good idea of the approximate cost of manufacture. The figures are based 
upon results obtained in the manufacture of cottage cheese in a commercial way at the creamery at Grove City, Pa., and, with the exception of the item of power, were obtained by making the proper tests to ascertain the expense of the different items. The labor represents the actual time of the men who did the work, figured at the rate which the average creamery would have to pay for the desired kind of help.

By making tests on the boiler to determine the number of pounds of water evaporated by 1 pound of coal, and by weighing the pounds of condensed steam required to Pasteurize and later heat the milk to separate the curd, the cost of fuel was ascertained. The soft coal used cost $\$ 4$ a ton, mine run. The costs of power and cooling are estimated at figures considered sufficiently high to cover these items. The quantity of water required to cool 1,000 pounds of skim milk

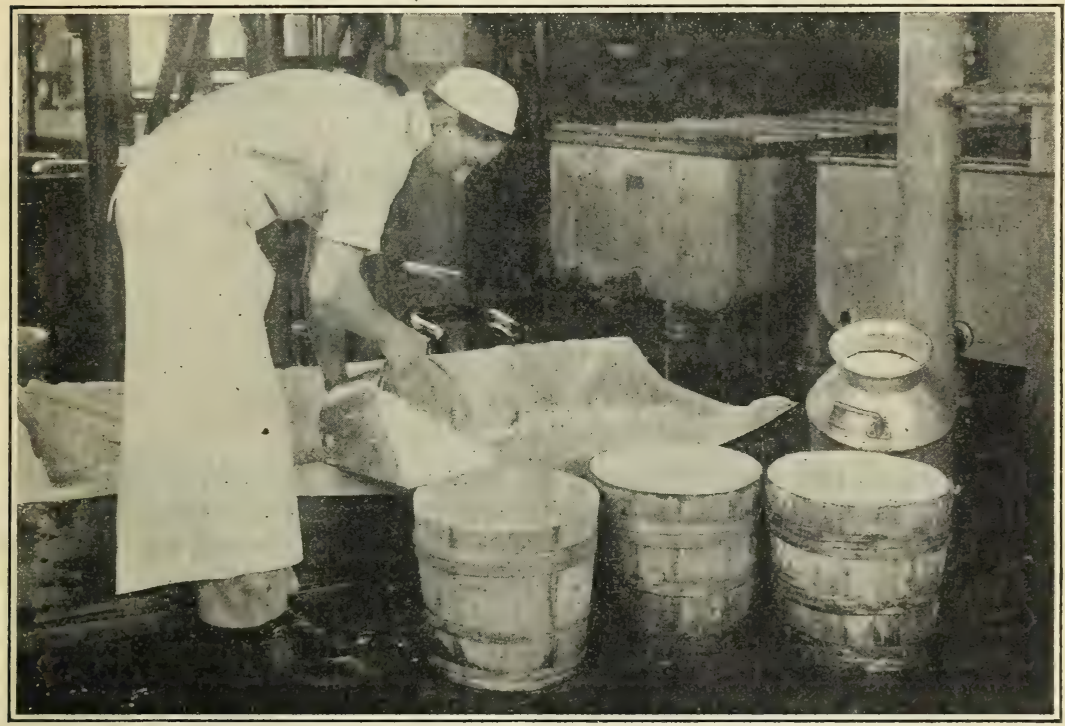

FIG. 5.-Packing the cheese in tubs. Here the drain rack with cloths is being used

was determined by measuring the actual water used to cool certain batches of Pasteurized milk. The cost of this was figured at the rate of 5 cents per 1,000 gallons.

Depreciation reserve was figured on the following basis:

\begin{tabular}{|c|c|c|c|}
\hline Apparatus & Value & $\begin{array}{l}\text { Probable } \\
\text { life }\end{array}$ & $\begin{array}{c}\text { Annual } \\
\text { deprecia- } \\
\text { tion }\end{array}$ \\
\hline \multirow[t]{2}{*}{$\begin{array}{l}\text { Pasteurizing vat......- } \\
\text { Making vat_. }\end{array}$} & \multirow[t]{2}{*}{$\begin{array}{r}\$ 750 \\
225\end{array}$} & \multirow[t]{2}{*}{$\begin{array}{l}10 \text { years } . . . . \\
2 \frac{1}{2} \text { years } . . .\end{array}$} & $\begin{array}{r}\$ 75 \\
90\end{array}$ \\
\hline & & & 165 \\
\hline
\end{tabular}

Taking 300 as the probable number of days the vat would be used gave a daily depreciation of 55 cents. The number of days the vat 
was used each month and the quantity of milk handled during the same period afford a basis for determining the charge for depreciation per 1,000 pounds of skim milk.

The following figures were used in obtaining the charge for interest on investment:

\begin{tabular}{|c|r|}
\hline Apparatus & Value \\
\hline Pasteurizing vat_..................... & $\$ 750$ \\
\cline { 2 - 2 } & 225 \\
\hline & 975 \\
\hline
\end{tabular}

The interest on $\$ 975$ at 6 per cent amounts to $\$ 58.50$ a year. Twenty-six runs a month, handling 5.000 pounds each, gives 18.7 cents a day, which makes an interest charge of 3.7 cents on 1,000 pounds of skim milk.

\section{Estimated cost of manufacturing cottage cheese}

\begin{tabular}{|r|r|}
\hline Item & $\begin{array}{r}\text { Cost per 1,000 } \\
\text { pounds milk }\end{array}$ \\
\hline Labor._. & $\$ 1.106$ \\
Power & .111 \\
Cooling water & .185 \\
Depreciation reserve....... & .037 \\
\hline Interest on investment.... & 1.704 \\
\hline Total & \\
\hline
\end{tabular}

The cost of the above items is figured on the basis of 1,000 pounds of skim milk because of the greater variation which would be shown when figuring on the basis of pounds of cottage cheese, as the result of the variation in yield.

On the basis of a yield of 17 pounds per 100 pounds of skim milk, the cost per pound of cheese would be $\$ 0.01002$, almost exactly 1 cent a pound, with no allowance for cost of package. These figures may be lowered with an increased volume of business; a decreased volume would raise them. When only a small quantity of cheese is made, the regular creamery force may be able to do the work without any additional help, which would be an item of importance in determining the actual cost.

\section{BUTTERMILK AS MATERIAL FOR CHEESE}

Buttermilk has occasionally been substituted for part of the skim milk in manufacturing cottage cheese. Where buttermilk is employed it should be utilized as soon as possible after coming from the churn, before any undesirable flavor develops. In general, the use of buttermilk as material for cottage cheese is not advised, unless the buttermilk is made from fresh, sweet. Pasteurized cream: and then in quantities of less than 25 per cent of the total amount of skim milk. 
Creameries having only buttermilk from fresh, sweet, Pasteurized cream can make it into a fair grade of buttermilk cheese. The curd may be precipitated from the soured buttermilk either by the vat method or by running the buttermilk through the ejector to heat it to the required temperature.

Because of the fineness of the curd in buttermilk, extreme care must be taken in heating to avoid breaking it up still finer. The amount of stirring required to bring the temperature of a vat full of buttermilk up to the proper point has a tendency to break up the curd so that a portion of it is liable to be lost during the process of draining. Running the buttermilk through the ejector heats it with the least possible breaking up of curd. By that method the curd is separated clearly and quickly from the whey and invariably rises to the top, facilitating a quick removal of the larger portion of the whey and making it possible to obtain the finished cheese in a short time. By means of a valve in the pipe leading from the buttermilk tank to the ejector and one in the steam pipe next to the ejector, the temperature to which the buttermilk is heated can be controlled easily. The proper temperature necessary for separating the curd clearly and quickly can be obtained readily by using a glass tumbler to catch samples of the heated buttermilk as it comes from the ejector. At the proper temperature the curd quickly rises to the top, and the whey is clear. By varying the temperature the proper degree of heat required is determined.

\section{MARKETS AND PRICES}

In cities where large industrial concerns employ foreign labor there is already a good demand for cottage cheese, and a satisfactory market usually can be developed in other cities or localities. The market demands and prices fluctuate considerably with the condition of the milk supply and the season of the year. An overabundance of milk makes more skim milk available for cottage cheese, thus tending to lower the price. As a whole the best market at the most favorable prices is afforded during the winter, with the heaviest demand during the Lenten season. The lighter market in the summer may be attributed to a greater supply of available skim milk and to the fact that warm weather makes it more difficult for dealers to handle the cheese, and in some cases prohibits the trade. Dealers who make a specialty of handling cottage cheese assert that they are in a position to buy and dispose of large quantities of the product throughout the year, the price being governed by the quality of the cheese and the condition of the milk supply.

The Grove City Creamery began the manufacture of cottage cheese for the purpose of utilizing skim milk and buttermilk to the best advantage and of providing a market, at an attractive price, for the skim milk of those patrons who wished to leave it at the creamery. The business was begun in a small way, and because of other outlets through which the raw material could be disposed of to fairly good advantage no organized effort was made to develop a market that would take care of the increased receipts of skim milk. At Grove City the winter price received for the cheese without the addition of 
cream, packed in cans or tubs furnished by the buyer, varied from 4 to 6 cents a pound $\mathrm{f}$. o. b. the point of manufacture. The wholesale price received for smoother-grained cheese, to which cream had been added at the rate of 1 pound to 10 of cheese, and which yielded from 17 to 18 pounds per hundred pounds of skim milk, packed in the 12-ounce, single-service containers, was 8 cents a package net at the creamery, or at the rate of $102 / 3$ cents a pound. The 12 -ounce cartons, including the shipping box, cost about 2 cents apiece. When filled with cheese of good quality they retail ordinarily for from 10 to 12 cents. The demand for cheese packed in the single-service containers is from the grocery stores and meat markets in the near-by towns.

It is very desirable that a uniform quality of cheese be made at all times in order that the trade that has been built up may be retained.

\section{SUMMARY}

Cottage cheese made from a good quality of skim milk is a most palatable and nutritious article of food.

Good raw material is essential for making a good product.

The Pasteurization of skim milk is recommended, because it insures a food free from all danger of disease-producing bacteria and gives more favorable conditions for the manufacture of a uniform, high-quality cheese.

The main equipment necessary for making cottage cheese from Pasteurized skim milk consists of a Pasteurizing outfit and a channelbottomed Cheddar-cheese vat.

From 2 to 10 per cent of a good lactic-acid starter is added to skim milk, then the milk is allowed to ripen at a temperature of $70^{\circ}$ to $75^{\circ} \mathrm{F}$. in the summer and $80^{\circ}$ to $85^{\circ}$ in the winter. A smooth, uniform curd is usually obtained in 10 to 15 hours. The curd is cut into cubes and gradually heated to $115^{\circ}$ to $125^{\circ} \mathrm{F}$. in one-half hour to one and one-half hours.

When the whey has been removed, the curd is washed first with warm and then with cold water, drained, and piled along the sides of the vat.

The cheese is salted at the rate of 3 to 4 ounces of salt per 100 pounds of skim milk, and then packed in cartons or butter tubs.

Skim milk of good quality should give a yield of from 15 to 18 pounds of cheese per 100 pounds of milk.

Cottage cheese should have a clean, mild acid flavor. The body and texture should be soft, smooth, and uniform throughout.

The cost of manufacturing cottage cheese is low, depending upon the volume of business and the additional equipment necessary. Under ordinary conditions the estimated cost of manufacture, not including packages or overhead charges, is approximately 1 cent a pound.

Glass containers and small, single-service, paraffined-paper containers are excellent for marketing cheese. These containers are very convenient for the dealer to handle and keep the product in good condition. 

